\title{
MINIMIZING TOTAL PRODUCTION COST IN A HYBRID FLOW SHOP: A SIMULATION-OPTIMIZATION APPROACH
}

\author{
Istokovic, D. ; Perinic, M. ; Vlatkovic, M. ${ }^{*} \&$ Brezocnik, M. ${ }^{* *}$ \\ ${ }^{*}$ University of Rijeka, Faculty of Engineering, Vukovarska 58, 51000 Rijeka, Croatia \\ ** University of Maribor, Faculty of Mechanical Engineering, Smetanova 17, 2000 Maribor, Slovenia \\ E-Mail: distokovic@ riteh.hr, mperinic@ riteh.hr, mmarkovic2@ riteh.hr, miran.brezocnik@um.si
}

\begin{abstract}
To ensure the competitiveness of manufacturing companies in the market, batching and batch scheduling are among the most important tasks. This paper presents a simulation-optimization approach that combines the discrete event simulation (DES) and the genetic algorithm (GA) to solve the batching and batch scheduling problem in a hybrid flow shop (HFS). HFS is widely used for the production of medium and large quantities of different technologically complex products. Based on a real-world manufacturing company, the HFS simulation model was developed using the Tecnomatix Plant Simulation software package. By analysing the influencing factors that represent production costs, a new formulation of the total cost of production was proposed. The purpose of this case study was to ensure timely delivery and minimize production costs by integrating simulation and optimization tools. This research considers sequence-dependent setup times, and availability of manufacturing and transportation equipment. The results of this research showed that the proposed simulation-optimization approach can be applied to solve the problem in many industrial case studies.
\end{abstract}

(Received in June 2020, accepted in November 2020. This paper was with the authors 2 months for 2 revisions.)

Key Words: Hybrid Flow Shop, Batching, Batch Scheduling, Production Cost, Discrete Event Simulation, Genetic Algorithm

\section{INTRODUCTION}

In today's ever-changing market circumstances, one of the key factors in ensuring the survival and competitiveness of manufacturing companies is production planning. When added to that the demands for ever-increasing product diversity and variable production volumes, production planning becomes even more important. Production planning is actually a complex area with a very large impact on the performance of a manufacturing company. In the detailed planning of production, among the most difficult tasks are decisions related to batching and batch scheduling. The batching problem involves dividing the total production quantity into unit batches in order to optimize certain criteria. Thereafter, by determining the order, the available production resources are allocated to the batches over a period of time [1].

In recent years, significant research efforts have been made in this area in the development of optimization approaches. Although significant progress has been made, to address a large number of operational issues (e.g., variable or fixed batch sizes, storage and transport rules, setups, tool replacements) as well as various objectives (e.g., makespan, earliness or cost minimization) many issues related to the specific possibilities of the methods still remain unresolved. Especially when considers the advantages and limitations of the different optimization methods used in the literature and the size of the problems that can realistically be solved with these methods.

Looking at the real world, HFS is the preferred choice for process and discrete manufacturing companies for production management to order and mass customization. HFS is widely used in many industries such as machinery manufacturing, automobile manufacturing, electronics manufacturing, and chemical manufacturing [2]. It is characterized by the production of medium or large quantities of several different types of products. The products move in one direction through the process and are processed on several workstations. Within 
each workstation there may be one or more identical machines, where each machine can perform at most one operation at the same time of any task [3]. Once started, the operation on the machine must not be interrupted. An operation of a task cannot be performed until the previous operations of that task have been completed. All tasks are subject to priorities that limit them to the same order of processing at all stages of processing.

This paper focuses on determining the batch size and batch sequence of products in a hybrid flow shop with the aim of satisfying on-time delivery and reducing total production costs. The HFS simulation model is modelled on a real-world manufacturing company. For detailed research, a simulation-optimization approach has been developed that combines discrete event simulation (DES) and a genetic algorithm (GA). The number and arrangement of machines in the observed system are fixed, as well as the processing time. Special attention is focused on the setups of the workplace and transportation, which are often neglected in the literature. Setups of the workplace is necessary upon the arrival of each new batch of products (it depends on the sequence) because it is necessary to ensure the smooth running of the operation. This includes the tasks of supplying and installing tools, clamping accessories, calibration of tools and workpieces, checking the first workpiece in the batch and more. Also, the impact of transportation availability as well as the time required to transfer a certain amount of product between workstations greatly contributes to the increase of waiting times.

The work is organized as follows. Section 2 provides an extensive overview of achievements to date in the field of production planning with a focus on simulation methods and optimization tools used in HFS. The developed simulation-optimization approach is described in Section 3, and the production cost is formulated in Section 4. Section 5 describes the HFS simulation model, while the Section 6 shows a real sector case study applied to the developed simulation model, and the obtained results. Finally, conclusions related to the obtained results are given.

\section{BACKGROUND AND LITERATURE REVIEW}

Many authors have worked on finding better ways of production planning developing different stochastic models. A review of publications with a focus on production operation planning and order planning was provided by Negahban and Smith [4]. Framinan et al. [5] show an integrated view of the models, methods and tools used in production planning.

Among the most difficult tasks of production planning are batching and batch scheduling. For plants with serial type of production, according to Mendez et al. [1], the appearance of the process and its topological implications have a significant impact on the complexity of the problem. Depending on whether the system consists of one or more phases, each phase may contain one or more parallel machines. It also depends on whether jobs are moving through the system in one direction or there is a return stroke. The batch scheduling problems in flow shop, Ribas et al. [2] are classified into: Parallel Machine Scheduling (PMS) - order planning problems in single-stage systems where there are multiple parallel machines that can perform the task, and Flow Shop Scheduling (FSS) where all jobs require processing on the same resources and they all have a common route. HFS is characterized by high productivity and low flexibility, which results in extremely little time space for manipulation in production process to take place in order to avoid delivery delays. Therefore, great attention should be paid to the setup times and the availability of transport equipment. An increasing number of papers is involving sequence-dependent setup times (SDST) in solving batch scheduling problems [6]. A review article related to the scheduling problem where setup times depends on the product sequence was given by Allahverdi [7]. The problem of availability of transport equipment was solved by Yang et al. [8]. 
In addition to the scheduling problems, in the literature can be found numerous works related to the batching problem. Batching problem priority refers to determining the size of the batches. The influence of batch size can be observed through the prism of time and through the prism of cost [9]. Observing through the prism of time, the size of the batches directly affects the flow time and the total setup times. Large batches extend the flow time but reduce the total setup times, in contrast to small batches where the flow time decreases and the total setup time increases [10]. From a cost standpoint, batch size has a direct impact on setup costs and inventory costs. Production that takes place in large batches will result in an increase in inventory costs but a reduction in the setup cost. On the other hand, production in smaller batches has lower inventory costs and higher setup costs [11].

For problems of determining the order and size of batches, the authors rely on mathematical techniques and heuristic methods that allocate resources (e.g., machines, transport equipment, workers, and others) to the tasks to be performed [12-15]. In doing so, they evaluate different performance measures (makespan, flow time, due dates, manufacturing costs, and so on).

Many authors deal with costs in production. Thus, the setup cost was dealt with by $\mathrm{Li}$ and Milne [16]. With the problem of order and batch scheduling in a single-machine environment with delivery delay costs involved has been addressed by Ahmadizar and Farhadi [17]. Yin et al. have considered the scheduling problem with the aim of reducing total costs [18]. Total costs, which include production costs, delivery costs, and inventory costs in a single-machine environment, were considered by Cheng et al. [19].

Furthermore, to optimize some of the performance measures, the authors use various optimization tools, such as: simulated annealing, evolution algorithms, particle swarm optimization [20] and others. However, real-world problems are very difficult to solve using only optimization tools because the speed of convergence and the efficiency of algorithms is usually slow for complex optimization problems. On the other hand, one of the most commonly used techniques for analysing production systems is DES. The reason lies in the fact that it enables the creation of a digital model of the real production system and simple subsequent changes without interfering with the operation of the actual system. It can also be used to evaluate and determine various alternatives to production configurations and operational strategies [4]. An important advantage of DES is that it can consider the uncertainties that are characteristic for real systems (e.g., machine failure, waiting, etc. Due to its great flexibility, DES has been widely applied in the design and operation of production systems [21-23]. However, if used separately, DES is not able to help find optimal solutions [24]. Linking simulation methods with optimization tools has been recognized as a promising solution, therefore, an increasing number of studies combining simulation and optimization to solve complex problems can be found in recent literature. In a broader sense of the production optimization, some papers discuss case studies that analyse advanced technologies contributing to the optimization of production costs (see, for example, [25]).

Plant Simulation software is increasingly used to optimize production performance, which, in addition to powerful simulation logic, also offers the possibility of combining with some optimization tools. Pekarcikova et al. have proposed in their paper the introduction of Kanban logic in material flow control to improve productivity, machine utilization and working time [26]. Shi et al. [27] use Plant Simulation to optimize makespan, total energy consumption, and total carbon emissions for their mathematical model based on sustainable hybrid flow shop with dynamic scheduling unit. The same software was used by Shibin et al. [28] for a case study of car manufacturing focusing on reducing energy consumption. Dong and Medeiros use this software to minimize the total cost of production. The total cost of production was viewed as the sum of storage costs, setup costs and costs of delayed delivery [29].

Based on the researched literature, this paper presents a simulation-optimization approach for solving the batching and batch scheduling problem of HFS with sequence dependent setup 
times, as well as included transport and uncertainties. Also, the analysis of influential factors that make up costs of production is defined and formulated the total production cost.

\section{SIMULATION-OPTIMIZATION APPROACH}

The purpose of this research is to integrate simulation and optimization tools to take advantage of both tools. On one hand, the discrete event simulation enables the creation of a digital model of the actual production system and the analysis of the existing situation without interfering with the operation of the actual system. It also ensures the inclusion of uncertainties specific to the actual system (e.g., machine failure, waiting, etc.). On the other hand, the genetic algorithm provides the ability to find optimal (or almost optimal) solutions. The application of the simulation-optimization approach to solve the batching and batch scheduling problem allows determining the order of entry of product batches into the system and the size of the batch in order to meet some of the performance measures, shown in Fig. 1.

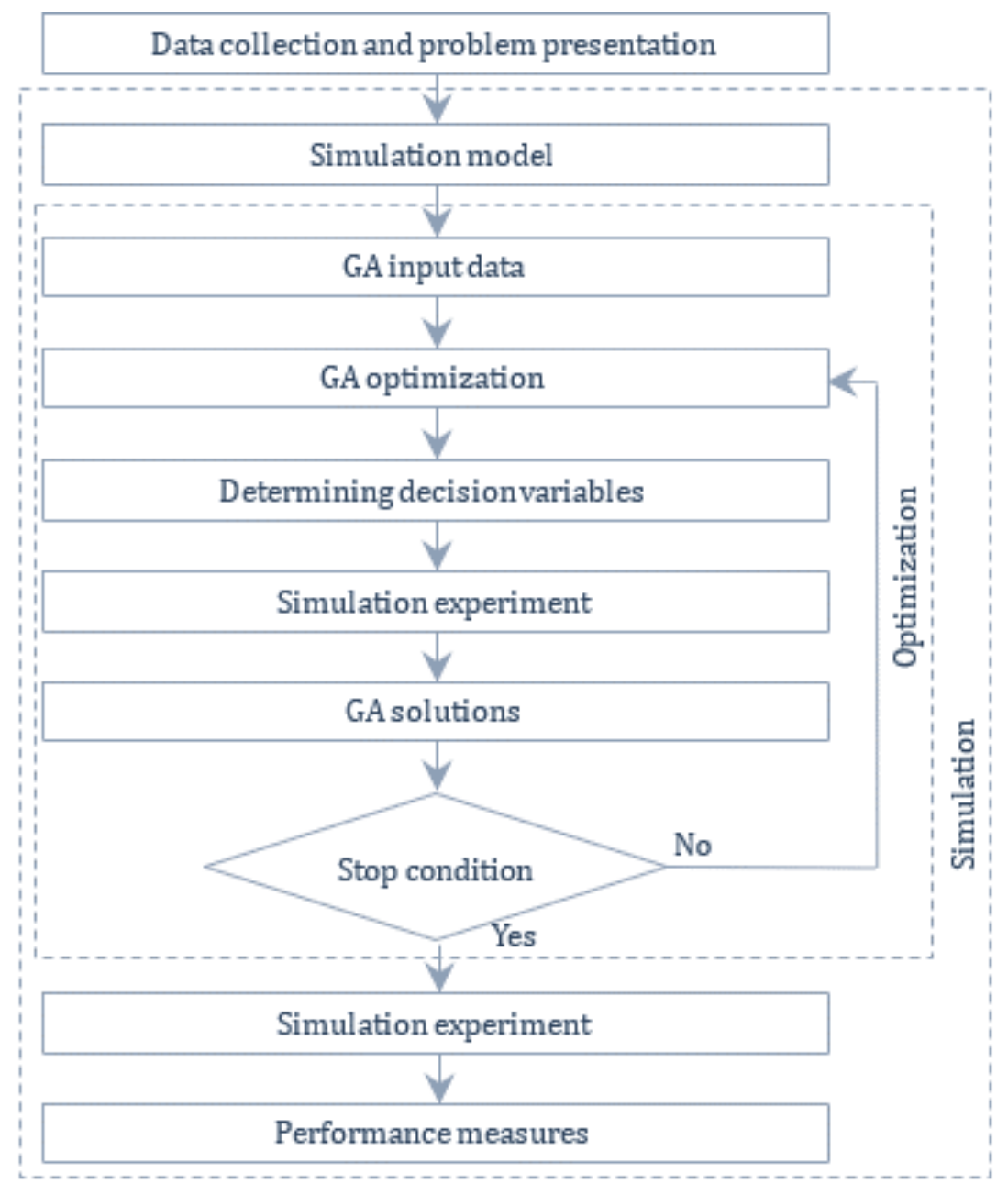

Figure 1: Scheme of simulation-optimization approach.

The collected data on the observation system and the defined research problem are implemented in the developed simulation model. The loop defined by the GA input parameters is then started. GA determines the input variables and starts the execution of simulation experiments for the defined input variables. Each simulation experiment generates solution. In doing so, GA strives to find the best possible solution (strives to find the minimum or maximum value of the objective function). The procedure is repeated until the stop condition is met. Upon completion of the optimization, optimal solutions were obtained for the input variables that are 
entered into the simulation model. A simulation experiment is performed again that will result in optimal values for some of the required performance measures.

\section{PRODUCTION COST FORMULATION}

What characterizes each production is to ensure delivery on time with the lowest possible production costs. This means that it is not necessary to produce the given quantities in the shortest possible time, but it is important that the money spent is as small as possible. Therefore, with Eq. (1), the total cost of production (TC) is formulated. It consists of the cost of production equipment, the cost of tools, the cost of storage, the cost of scrap, the cost of raw materials, the cost of energy, and the cost of delayed delivery.

$$
T C=\left(C_{M E}+C_{T}+C_{R P}+C_{S}+C_{P}+C_{E C}\right) \cdot k_{P E N}
$$

In serial production in HFS, manufacturing equipment is used only for the specified production process, which means that manufacturing equipment represents a cost for the entire duration of production, i.e., for the observed period. It consists of machines, transport and control equipment and is used as a resource actively and passively in the observed period. Active use of machines is related to the time required to perform operations, while passive use of machines refers to inter-operational waits, namely the setups, tool replacements, downtime due to failure (unreliability), product waiting in line for processing and transporting (next workplace or warehouse of finished products), as well as waiting when machines are not working because all products are processed. The control equipment is actively used during the final control, and all waiting times for the inspection of the next workpiece represent the passive use of the control equipment. Active utilization of transport equipment refers to the time while the products are being transferred, while the rest of the time the transport equipment is at a standstill. The cost of manufacturing equipment is given by Eq. (2), where $T_{\max }$ is end time of the observed period (can take the values of $C_{\max }$ or $C_{\max , g o a l}$ ) and $A V_{m}, A V_{k}$ and $A V_{t}$ represent depreciation values of $m$ machine, $k$ control equipment and $t$ transport equipment.

$$
C_{M E}=T_{\text {max }} \cdot\left(\sum_{m=1}^{o} A V_{m}+\sum_{k=1}^{p} A V_{k}+\sum_{t=1}^{r} A V_{t}\right)
$$

The cost of tools depends on the number of tools used. It is calculated according to Eq. (3), as a product of the total quantity and cost of tools used through the observed period on $\mathrm{m}$ machine.

$$
C_{T}=\sum_{m=1}^{o} \sum_{a=1}^{q} N_{a m} \cdot C_{a m}
$$

The occurrence of scrap can have a multiple effect on the increase in total cost. This refers to the additional occupancy of machines and a possible increase in the number of tools used. Also, the occurrence of scrap prolongs the process and this can lead to delayed delivery. These impacts represent the costs retained in the cost of manufacturing equipment, the cost of tools and the cost of delayed delivery. However, the occurrence of scrap also affects the increase in the required quantity of raw materials. Therefore, the cost of scrap is calculated according to Eq. (4), as a product of the amount of reject parts $R P$ and the price of raw materials $C_{j}$.

$$
C_{R P}=\sum_{j=1}^{n} \sum_{i=1}^{m} R P_{i j} \cdot C_{j}, \quad \forall j=R P
$$

One of the most important costs to pay attention to is the storage cost. Depending on the production quantities and dimensions of the product (semi-finished product, finished product), 
as well as its value, this cost is more or less important. It is not desirable for the product to be stored. It is ideal when goods or services are delivered just in time. In reality, however, this is extremely risky and practically impossible to achieve, but it is being pursued. It should be emphasized that the price of raw materials storage and finished goods storage is not the same. Therefore, it is desirable that the finished products spend as little time as possible in the finished goods storage because they have a relatively high value. On the other hand, in order for the raw material not to stay in the raw materials storage for a long time, the supply of material at several intervals can be ensured. The storage costs $C_{S}$ can be divided into two parts, Eq. (5), the cost of storing the raw materials $C_{S R M}$ and the cost of storing the finished goods $C_{S F G}$. The $C_{S R M}$ can be shown as the time that the raw material spends in the raw material storage multiplied by the cost of storing the raw materials, while the $C_{S F G}$ is the product of time that finished products spends in the finished goods storage multiplied by the cost of storing the finished products, see Eqs. (6) and (7). In doing so, the $A_{b j}$ represents entry time of batch $b$ of product $j$ in system (leaving the raw materials storage), $t_{0}$ is a start of production (zero time), $L S_{j}$ is batch size of product $j, C_{s r m, j}$ represents a storage cost of one $j$ raw material, while $T_{\max }$ represents end time of the observed period (can take the values of $C_{\max }$ and $C_{\max , g o a l}$ ), $E_{b j}$ represents entry time of batch $b$ of product $j$ into the finished goods storage, and $C_{s f g, j}$ is the storage price of one $j$ finished product.

$$
\begin{gathered}
C_{S}=C_{S R M}+C_{S F G} \\
C_{S R M}=\sum_{j=1}^{n} \sum_{b=1}^{h}\left(A_{b j}-t_{0}\right) \cdot L S_{j} \cdot C_{S r m, j} \\
C_{S F G}=\sum_{j=1}^{n} \sum_{b=1}^{h}\left(T_{\max }-E_{b j}\right) \cdot L S_{j} \cdot C_{s f g, j}
\end{gathered}
$$

The term energy cost means how much energy is consumed for the production process in the observed period. This primarily refers to the consumption of electricity, because machines and transport equipment are most often powered by electricity and will be observed in this way. It should be considered that energy consumption is not uniform (start-up of manufacturing equipment, uninterrupted operation, downtime, etc.). The energy $\operatorname{cost} C_{E C}$ is equal to Eq. (8), i.e., equal to the consumed electricity of machines $E_{m}$ and the transport equipment $E_{t}$ multiplied by price of electricity $C_{e}$.

$$
C_{E C}=\left(\sum_{m=1}^{o} E_{m}+\sum_{t=1}^{r} E_{t}\right) \cdot C_{e}
$$

Also, the cost of production should include the cost of raw materials. The cost of raw materials $C_{P}$, Eq. (9), is reflected as the product of the production quantity $q_{j}$ and the price of $j$ raw material $C_{j}$. The price of raw materials may vary due to the volatility of market prices. This impact of the volatility will not be considered in this paper, but is considered as a fixed quantity.

$$
C_{P}=q_{j} \cdot C_{j}
$$

The last and most unfavourable cost that arises is the cost due to delays in the delivery of agreed quantities because in addition to increasing the cost of production, it also negatively affects the competitiveness of the manufacturing company. The cost of delivery delay or penalties is the cost that is added to the total cost of production in the form of a percentage amount to the total value of late delivery of goods. It is displayed as a delivery delay coefficient, $k_{P E N}$. It should be noted that $k_{P E N}=1$, if the agreed production quantity is delivered on time. If the delivery of the agreed production quantity is delayed, then the coefficient of late delivery is calculated according to Eq. (10). It is worth noting that $P_{j}$ represents the penalty rate for nondelivery of the $j$ product. 


$$
k_{P E N}=\left(C_{\max }-C_{\max , \text { goal }}\right) \cdot P_{j}, \quad \forall\left(C_{\max }-C_{\max , \text { goal }}\right)>0
$$

\section{HYBRID FLOW SHOP (HFS) SIMULATION MODEL}

The HFS simulation model is based on a real-world production system. Like any HFS, it is characterized by the production of medium or large quantities of several types of products that are processed by different technological processes. Through the system, all products move unidirectional and are subject to the same order of operations. The products are processed inside workstations that can consist of several identical machines. In doing so, each machine can process all types of products according to the defined processing times for each product.

It was stated earlier that one of the most important tasks of production planning is to determine the order and size of the batch. While batch size is easy to display as a numeric value, this is not the case for order of product batches. Therefore, in order to determine the entry sequence of batches, the probability of batch entry is used in this paper. Batch entry probability and batch size are decision variables used to optimize some of the performance measures. Specifically, in this case to minimize the cost of production. The decision variables can be represented as a chromosome, according to Fig. 2, as a series of genes where $L S_{j}$ represents the gene for the batch size of the $j$ product, and $P E_{j}$ represents the gene for the probability of batch entry. The number of genes depends on the number of different types of products.

\begin{tabular}{|l|l|l|l|l|l|l|l|l|l|}
$L S_{1}$ &.. & $L S_{j}$ &.. & $L S_{n}$ & $P E_{1}$ &.. & $P E_{j}$ &.. & $P E_{n}$ \\
\hline
\end{tabular}

Figure 2: Chromosome for batch size and batch entry.

According to the defined order, batches of products enter the production system at a certain point in time. Each batch of products contains a defined unit quantity of products. Upon arrival at one of the workstations, the product batch is unpacked at a common intermediate storage in charge of directing the product towards the machines using FIFO logic. With the arrival of a different batch of products for processing, there is a need for setup of the workplace, Eq. (11). Setup time is determined according to a uniform distribution. During this time, all the necessary activities are performed for the smooth running of operations, including placing of appropriate tools. The blade of each tool has its own durability. If the tool blade processes the maximum amount of product before it becomes blunt, there is a need to replace the tool, which represent an additional limitation, Eq. (12). Tool replacement time is less than the setup time. It is also determined by a uniform distribution. It should not be forgotten that any machine can stop working due to a machine failure. The probability of failure has been estimated and is defined as the rate of failure. After all the products in the batch have been processed, at the output intermediate storage, they are prepared for transport to the next workstation or to the finished goods storage. The transfer of products between workstations is ensured by a transport equipment. By performing all operations, the batch of products is transported to the finished goods storage.

$$
\begin{gathered}
S T_{m}>0, \quad \forall b_{j} \neq b_{j-1} \\
T C T_{a}>0, \quad \forall T U_{a}=T U_{\max }
\end{gathered}
$$

\section{CASE STUDY, RESULTS AND DISCUSSION}

The case study was applied to a concrete example of a manufacturing company engaged in the production of technologically complex products. They wanted to improve simpler and more efficient production by grouping three technologically similar products into one production process with the aim of delivering on time and that the costs of the production itself are optimal. 
The maximum allowed time for processing these products is two weeks, i.e., $C_{\text {max }, \text { goal }}=80$ hours. The production system consists of five workstations in which is respectively 2, 3, 3, 1 and 2 machines. Each workstation is a phase in the production process where the production takes place. The layout of the production system, as well as the time (expressed in minutes, e.g., 3:30 represents 3 minutes and 30 seconds) and the sequence of operations are shown in Fig. 3 .

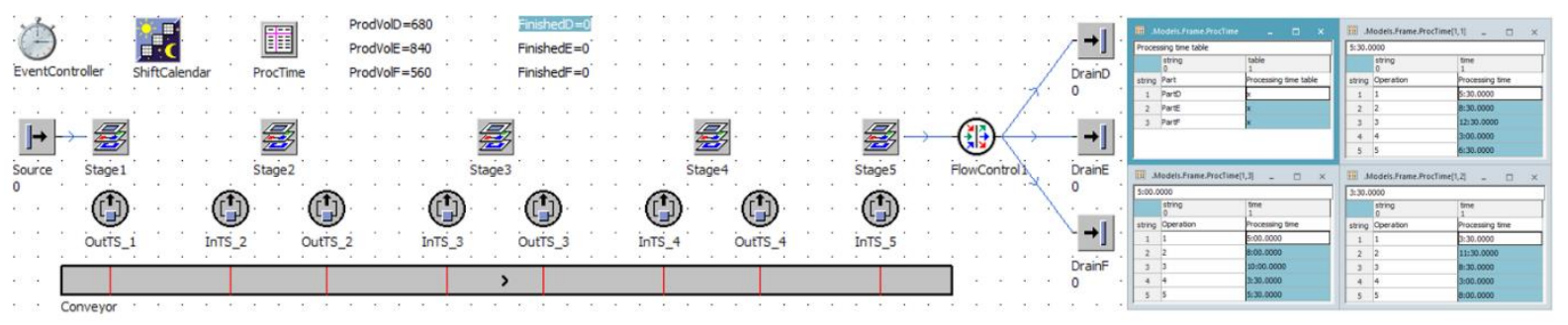

a)

b)

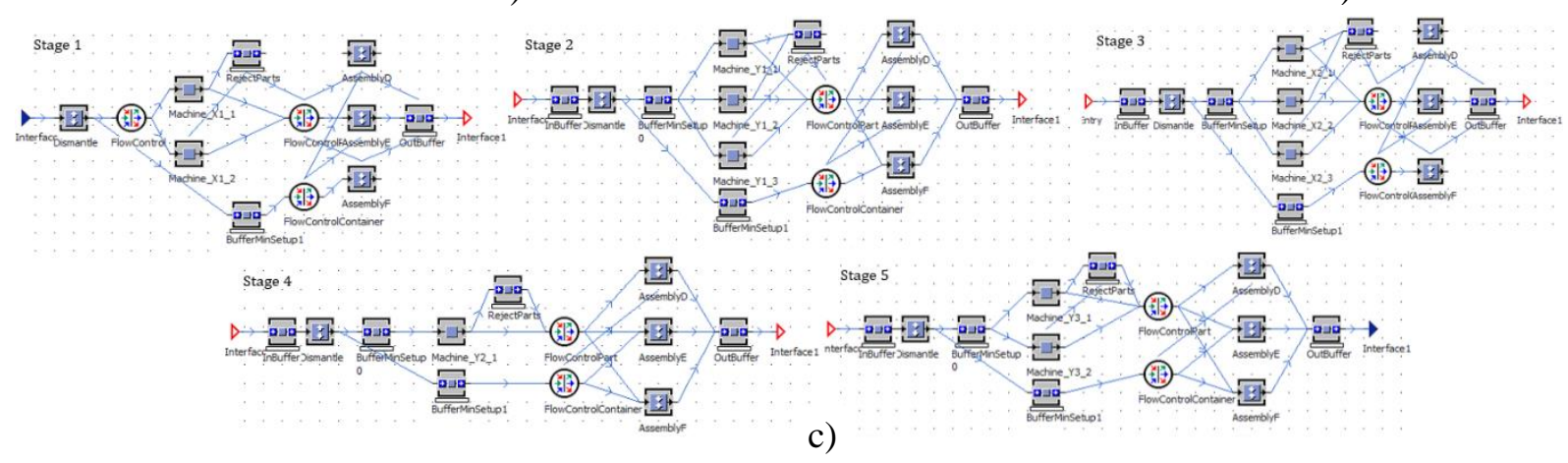

Figure 3: a) Hybrid Flow Shop, b) time and sequence of operations, c) layout of machines.

Setup times, machine availability, mean time to repair (MTTR) and the probability of occurrence of reject parts are given in Table I. Also, the values for the number of machines within each workstation and their depreciation value are given. The defined values are the same for all machines within one workstation because they are identical machines. Setup times are shown as uniformly distributed times. For example, setup time $U(5,15)$ means that the setup time varies in a range from 5 to 15 minutes. The depreciation value of the used control equipment is 700 currency units (CU) per day. The transfer of product batches is ensured by using a conveyor as a transport equipment whose depreciation value is $115 \mathrm{CU}$ per day.

Table I: Input data - machines.

\begin{tabular}{|c|c|c|c|c|c|c|}
\hline Stage & $\begin{array}{c}\text { Machine } \\
\text { quantity } \\
(\mathrm{pcs})\end{array}$ & $\begin{array}{c}\text { Setup time } \\
(\mathrm{min})\end{array}$ & $\begin{array}{c}\text { Machine } \\
\text { availability } \\
(\%)\end{array}$ & $\begin{array}{c}\text { MTTR } \\
(\mathrm{min})\end{array}$ & $\begin{array}{c}\text { Reject } \\
\text { parts } \\
(\%)\end{array}$ & $\begin{array}{c}\text { Depreciation value } \\
\text { (CU per day) }\end{array}$ \\
\hline 1 & 2 & $\mathrm{U}(5,15)$ & 98 & 10 & 2 & 100 \\
\hline 2 & 3 & $\mathrm{U}(20,45)$ & 97 & 15 & 3 & 1050 \\
\hline 3 & 3 & $\mathrm{U}(20,35)$ & 98 & 15 & 2 & 1450 \\
\hline 4 & 1 & $\mathrm{U}(10,30)$ & 95 & 10 & 5 & 200 \\
\hline 5 & 2 & $\mathrm{U}(10,20)$ & 95 & 10 & 5 & 240 \\
\hline
\end{tabular}

The price of each tool, the amount of product that can be processed before the blade wears out, and the average tool change time are given in Table II. For simplicity, only one type of tool is used on machines within the first, fourth, and fifth workstation, while second and third workstation uses three types of tools and tool replacement is applied to these machines due to blade wear. Also, it is worth noting that tools T1 and T2 are used for processing product D, tools $\mathrm{T} 1$ and $\mathrm{T} 3$ are used for processing product $\mathrm{E}$, while tool T2 is used for processing product F. The price of the tool used on the remaining three workstations is in order: $300,1800,1000$. 
Table II: Input data - tools.

\begin{tabular}{|c|c|c|c|}
\hline Tool & Tool cost $(\mathrm{CU})$ & Max. usage $(\mathrm{pcs})$ & Changeover time (min) \\
\hline $\mathrm{T} 1$ & 375 & 30 & 5 \\
\hline $\mathrm{T} 2$ & 575 & 30 & 4 \\
\hline $\mathrm{T} 3$ & 270 & 25 & 3 \\
\hline
\end{tabular}

Table III shows the production quantities for the given products and the price of the raw materials. It also shows the storage price of raw materials and finished goods. Storage costs are defined for one workpiece.

Table III: Input data - products.

\begin{tabular}{|c|c|c|c|c|}
\hline Product & $\begin{array}{c}\text { Quantity } \\
(\mathrm{pcs})\end{array}$ & $\begin{array}{c}\text { Raw material cost } \\
(\mathrm{CU} / \mathrm{pcs})\end{array}$ & $\begin{array}{c}\text { Storage RM cost } \\
\text { (CU per day) }\end{array}$ & $\begin{array}{c}\text { Storage FG cost } \\
\text { (CU per day) }\end{array}$ \\
\hline Part D & 680 & 9.92 & 2.5 & 20 \\
\hline Part $\mathrm{E}$ & 840 & 5.68 & 2.5 & 12.5 \\
\hline Part $\mathrm{F}$ & 560 & 6.51 & 2.5 & 20 \\
\hline
\end{tabular}

Once the simulation model is created, the optimization is started using the optimization tool, GA. By testing different values of GA parameters, the following values proved to be sufficient: number of generations was set to 50, population size to 50, and the number of observations to 5. Starting optimization, GA randomly determines the initial population with a defined number of individuals. Since three products are produced, each individual consists of six genes (three for batch size, three for batch entry probability). Then each individual is shown as a currency unit, calculated according to Eq. (1). In order to achieve this, a simulation experiment is performed for each individual. Furthermore, individuals are hierarchically ranked from smallest to largest in terms of currency unit. Roulette wheel selection chooses parents who are cloned and give offspring. In doing so, the individual with the lowest value is most likely to be selected as opposed to the one with the highest value who is least likely to be selected. After that, genetic operators are applied to the offspring: two points crossover, and mutation. The probability of crossover was set to 0.7 , while the probability of mutation was set to 0.15 . The above procedures result in new individuals for whom their currency unit is calculated, according to Eq. (1). GA then by probabilistic selection chooses between parents and offspring which individuals will be used in the next generation. Once the defined number of generations is reached, the best solutions are displayed.

To find solutions to the batching and batch scheduling problem using simulation and optimization approach was needed 59 minutes, which is a relatively short time to obtain solutions. The best solution obtained by optimization is shown in Table IV. The first three genes represent the batch size, while the remaining three represent the batch entry probability for products $\mathrm{D}, \mathrm{E}$, and $\mathrm{F}$.

Table IV: The best optimization solution.

\begin{tabular}{|l|l|l|l|l|l|}
\hline 86 & 118 & 99 & 315 & 337 & 251 \\
\hline
\end{tabular}

Optimization solutions are entered as decision variables into the simulation model. The simulation experiment is started again, which results in the sequence and entry time for product batches D, E and F, shown in Fig. 4. It can be noticed that the observed quantity of defined products can be produced and delivered on time, thus satisfying the basic condition. Also, Fig. 4 shows the cost of production for the observed products amounting to 377,992 currency units, which represents the optimal value of production costs. 


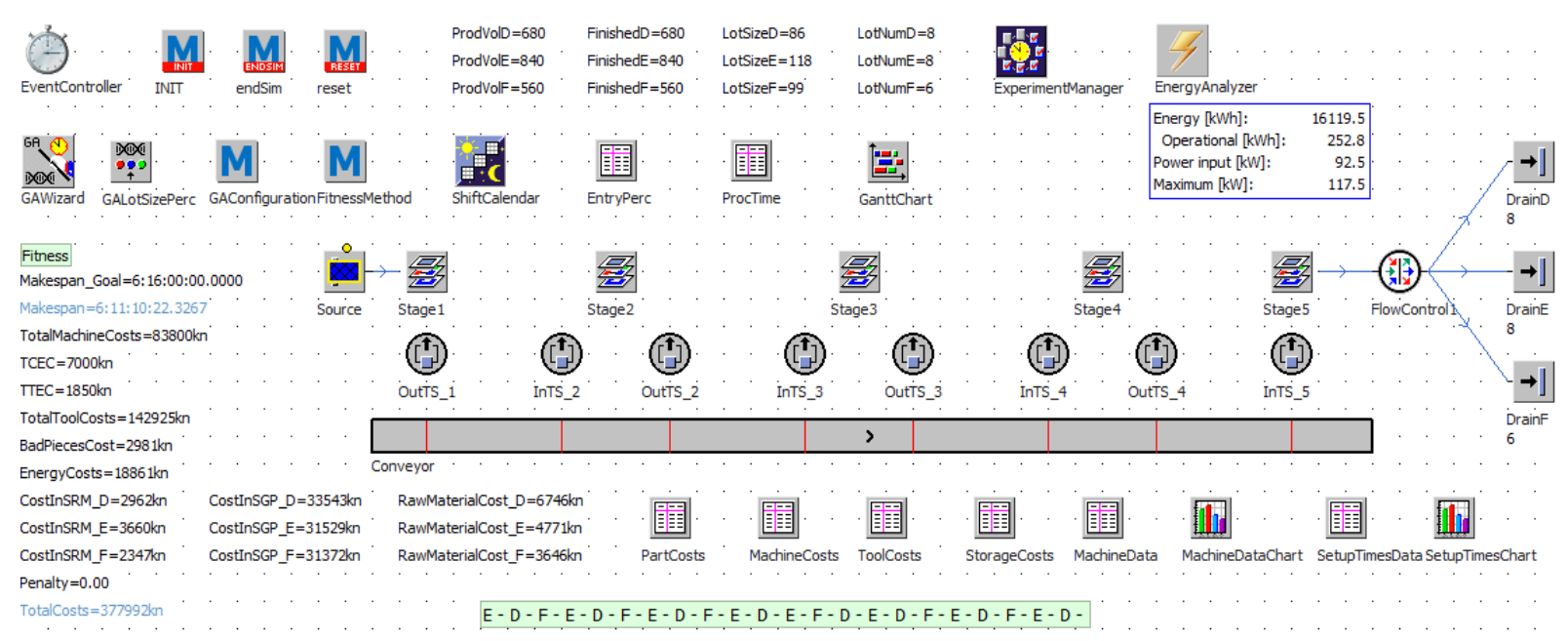

Figure 4: Final results of the case study.

\section{CONCLUSION}

This scientific research deals with the batching and batch scheduling problems in a Hybrid Flow Shop (HFS) with the sequence-dependent setup times (SDST) and transport involved. To solve the batching and batch scheduling problem, a simulation-optimization approach has been developed that combines a discrete event simulation and a genetic algorithm. In this way, we took advantage of both approaches. On the one hand, the discrete event simulation allows the creation of a digital model of the real system and analysis of the existing state without interfering with the operation of the real system and allows the inclusion of uncertainties characteristic for real systems (e.g., machine failure, waiting, and others). On the other hand, the genetic algorithm ensures relatively fast finding of optimal (or almost optimal) solutions.

The HFS simulation model is modelled on a real-world manufacturing company, using the Tecnomatix Plant Simulation software package. By analysing the influencing factors that represent production costs, a new formulation of the total cost of production is proposed.

The approach is applied to a specific example of a manufacturing company engaged in the production of technologically complex products. The idea of the production company was to improve production to be simpler and more efficient by grouping three technologically similar products into one production process with aim to deliver products on time and that the costs of production itself are optimal.

The solutions obtained by this approach show that a defined quantity of products can be produced and delivered on time. The proposed simulation-optimization approach finds solutions in a relatively short period of time allowing application to solve the problem in many industry case studies.

\section{ACKNOWLEDGEMENT}

This work was financially supported by University of Rijeka, Croatia, contract number 'uniri-tehnic-18223 ' and by University of Rijeka, Croatia, contract number 'uniri-tehnic-18-100'. The authors would like to thank the company iTCR d.o.o. for their extensive help.

\section{REFERENCES}

[1] Méndez, C. A.; Cerda, J.; Grossmann, I. E.; Harjunkoski, I.; Fahl, M. (2006). State-of-the-art review of optimization methods for short-term scheduling of batch processes, Computers \& Chemical Engineering, Vol. 30, No. 6-7, 913-946, doi:10.1016/j.compchemeng.2006.02.008 
[2] Ribas, I.; Leisten, R.; Framiñan, J. M. (2010). Review and classification of hybrid flow shop scheduling problems from a production system and a solutions procedure perspective, Computers \& Operations Research, Vol. 37, No. 8, 1439-1454, doi:10.1016/j.cor.2009.11.001

[3] Uzun Araz, O.; Eski, O.; Araz, C. (2019). A reactive scheduling approach based on fuzzy inference for hybrid flowshop systems, International Journal of Simulation Modelling, Vol. 18, No. 1, 5-18, doi:10.2507/IJSIMM18(1)448

[4] Negahban, A.; Smith, J. S. (2014). Simulation for manufacturing system design and operation: Literature review and analysis, Journal of Manufacturing Systems, Vol. 33, No. 2, 241-261, doi:10.1016/j.jmsy.2013.12.007

[5] Framinan, J. M.; Leisten, R.; Ruiz García, R. (2014). Manufacturing Scheduling Systems: An Integrated View on Models, Methods and Tools, Springer-Verlag, London, doi:10.1007/978-14471-6272-8

[6] Vinod, K. T.; Prabagaran, S.; Joseph, O. A. (2019). Dynamic due date assignment method: A simulation study in a job shop with sequence-dependent setups, Journal of Manufacturing Technology Management, Vol. 30, No. 6, 987-1003, doi:10.1108/JMTM-06-2017-0112

[7] Allahverdi, A. (2015). The third comprehensive survey on scheduling problems with setup times/costs, European Journal of Operational Research, Vol. 246, No. 2, 345-378, doi:10.1016/ j.ejor.2015.04.004

[8] Yang, S. L.; Xu, Z. G.; Li, G. Z.; Wang, J. Y. (2020). Assembly transport optimization for a reconfigurable flow shop based on a discrete event simulation, Advances in Production Engineering \& Management, Vol. 15, No. 1, 69-80, doi:10.14743/apem2020.1.350

[9] Ramya, R.; Rajendran, C.; Ziegler, H.; Mohapatra, S.; Ganesh, K. (2019). Capacitated Lot Sizing Problems in Process Industries, Springer Nature, Cham, doi:10.1007/978-3-030-01222-9

[10] Ištoković, D.; Perinić, M.; Doboviček, S.; Bazina, T. (2019). Simulation framework for determining the order and size of the product batches in the flow shop: A case study, Advances in Production Engineering \& Management, Vol. 14, No. 2, 166-176, doi:10.14743/apem 2019.2.319

[11] Drexl, A.; Kimms, A. (1997). Lot sizing and scheduling - Survey and extensions, European Journal of Operational Research, Vol. 99, No. 2, 221-235, doi:10.1016/S0377-2217(97)00030-1

[12] Esmaeilian, B.; Behdad, S.; Wang, B. (2016). The evolution and future of manufacturing: A review, Journal of Manufacturing Systems, Vol. 39, 79-100, doi:10.1016/j.jmsy.2016.03.001

[13] Sousa Junior, W. T. de, Montevechi, J. A. B.; Miranda, R. de C.; Rocha, F.; Vilela, F. F. (2019). Economic lot-size using machine learning, parallelism, metaheuristic and simulation, International Journal of Simulation Modelling, Vol. 18, No. 2, 205-216, doi:10.2507/IJSIMM18(2)461

[14] Brajković, T.; Perinić, M.; Ikonić, M. (2018). Production planning and optimization of work launch orders using genetic algorithm, Tehnicki vjesnik - Technical Gazette, Vol. 25, No. 5, 1278-1285, doi:10.17559/TV-20161207195125

[15] Modrak, V.; Soltysova, Z. (2020). Batch size optimization of multi-stage flow lines in terms of mass customization, International Journal of Simulation Modelling, Vol. 19, No. 2, 219-230, doi:10.2507/IJSIMM19-2-511

[16] Li, Q.; Milne, J. R. (2014). A production scheduling problem with sequence-dependent changeover costs, International Journal of Production Research, Vol. 52, No. 13, 4093-4102, doi: $\underline{10.1080 / 00207543.2014 .889860}$

[17] Ahmadizar, F.; Farhadi, S. (2015). Single-machine batch delivery scheduling with job release dates, due windows and earliness, tardiness, holding and delivery costs, Computers \& Operations Research, Vol. 53, 194-205, doi:10.1016/j.cor.2014.08.012

[18] Yin, Y.; Cheng, T. C. E.; Wang, J.; Wu, C.-C. (2013). Single-machine common due window assignment and scheduling to minimize the total cost, Discrete Optimization, Vol. 10, No. 1, 42 53, doi:10.1016/j.disopt.2012.10.003

[19] Cheng, B.-Y.; Leung, J. Y.-T.; Li, K. (2017). Integrated scheduling on a batch machine to minimize production, inventory and distribution costs, European Journal of Operational Research, Vol. 258, No. 1, 104-112, doi:10.1016/j.ejor.2016.09.009

[20] Omidinasab, F.; Goodarzimehr, V. (2020). A hybrid particle swarm optimization and genetic algorithm for truss structures with discrete variables, Journal of Applied and Computational Mechanics, Vol. 6, No. 3, 593-604, doi:10.22055/JACM.2019.28992.1531 
[21] Yang, S. L.; Xu, Z. G.; Li, G. Z.; Wang, J. Y. (2020). Assembly transport optimization for a reconfigurable flow shop based on a discrete event simulation, Advances in Production Engineering \& Management, Vol. 15, No. 1, 69-80, doi:10.14743/apem2020.1.350

[22] Herakovič, N.; Zupan, H.; Pipan, M.; Protner, J.; Šimic, M. (2019). Distributed manufacturing systems with digital agents, Strojniski vestnik - Journal of Mechanical Engineering, Vol. 65, No. 11-12, 650-657, doi:10.5545/sv-jme.2019.6331

[23] Gajsek, B.; Marolt, J.; Rupnik, B.; Lerher, T.; Sternad, M. (2019). Using maturity model and discrete-event simulation for Industry 4.0 implementation, International Journal of Simulation Modelling, Vol. 18, No. 3, 488-499, doi:10.2507/IJSIMM18(3)489

[24] Montevechi, J. A. B.; Miranda, R. de C.; Friend, J. D. (2012). Sensitivity analysis in discrete event simulation using design of experiments, Lim, E. W. C. (Ed.), Discrete Event Simulations Development and Applications, IntechOpen, Rijeka, 63-102, doi:10.5772/50196

[25] Prester, J.; Buchmeister, B.; Palčič, I. (2018). Effects of advanced manufacturing technologies on manufacturing company performance, Strojniski vestnik - Journal of Mechanical Engineering, Vol. 64, No. 12, 763-771, doi:10.5545/sv-jme.2018.5476

[26] Pekarcikova, M.; Trebuna, P.; Kliment, M.; Rosocha, L. (2020). Material flow optimization through e-Kanban system simulation, International Journal of Simulation Modelling, Vol. 19, No. 2, 243-254, doi:10.2507/IJSIMM19-2-513

[27] Shi, L.; Guo, G.; Song, X. (2019). Multi-agent based dynamic scheduling optimisation of the sustainable hybrid flow shop in a ubiquitous environment, International Journal of Production Research, in press, 22 pages, doi:10.1080/00207543.2019.1699671

[28] Shibin, K. T.; Gunasekaran, A.; Papadopoulos, T.; Childe, S. J.; Dubey, R.; Singh, T. (2016). Energy sustainability in operations: an optimization study, The International Journal of Advanced Manufacturing Technology, Vol. 86, No. 9-12, 2873-2884, doi:10.1007/s00170-016-8398-6

[29] Dong, S.; Medeiros, D. J. (2012). Minimising schedule cost via simulation optimisation: an application in pipe manufacturing, International Journal of Production Research, Vol. 50, No. 3, 831-841, doi:10.1080/00207543.2010.545447 